\title{
O processo administrativo disciplinar à luz da teoria do processo sancionador
}

rdai.com.br/index.php/rdai/article/view/413

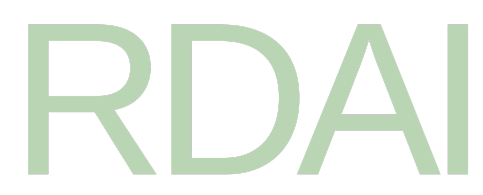

\section{Autores}

- Vladimir da Rocha França Universidade Federal do Rio Grande do Norte Rio (Natal, Rio Grande do Norte, Brasil).

- Giulliana Niederauer Flores Severo de Morais Universidade Federal do Rio Grande do Norte Rio (Natal, Rio Grande do Norte, Brasil)

\section{DOI:}

https://doi.org/10.48143/rdai.19.vrf

\section{Palavras-chave:}

Direito administrativo sancionador, Servidor público, Processo Administrativo Disciplinar, Teoria do Processo Sancionador, Cláusula do devido processo legal

\section{Resumo}

A relação estabelecida entre a Administração Pública e seus servidores públicos é regulada por estatuto, que prevê deveres, proibições e penalidades, sujeitando os funcionários ao poder-disciplinar, com a finalidade corretiva e punitiva, diante de infrações funcionais apuradas por meio de processo administrativo disciplinar. Partindo disso, compreende-se que os atos administrativos praticados dentro do processo administrativo disciplinar ostentam importantes efeitos processuais, devendo ser analisados à luz da teoria do processo sancionador. Por isso, o objetivo principal do presente artigo é identificar alguns princípios que fundamentam a teoria do processo sancionador, especialmente os seus efeitos jurídicos sobre os direitos fundamentais dos servidores públicos submetidos a procedimento disciplinar.

\section{Biografia do Autor}

\section{Vladimir da Rocha França, Universidade Federal do Rio Grande do Norte Rio (Natal, Rio Grande do Norte, Brasil).}


Professor de Universidade Federal do Rio Grande do Norte Rio (Natal, Rio Grande do Norte, Brasil). Doutor em Direito Administrativo pela Pontifícia Universidade Católica de São Paulo. Mestre em Direito Público pela Universidade Federal de Pernambuco. Associado do Instituto Brasileiro de Direito Administrativo. Associado fundador do Instituto de Direito Administrativo Sancionador Brasileiro. Associado fundador e presidente do Instituto de Direito Administrativo Seabra Fagundes. (iD o000-0001-99773617 | vrochafranca@gmail.com

\section{Giulliana Niederauer Flores Severo de Morais, Universidade Federal do Rio Grande do Norte Rio (Natal, Rio Grande do Norte, Brasil)}

Mestranda em Direito Constitucional pela Universidade Federal do Rio Grande do Norte. Especialista em Direito Constitucional pela Universidade Anhanguera. Aluna do PPGD da Universidade Federal do Rio Grande do Norte Rio (Natal, Rio Grande do Norte, Brasil). Associada do Instituto de Direito Administrativo Seabra Fagundes. 3008 | giullianasevero@gmail.com

\section{Referências}

BANDEIRA DE MELLO, Celso Antônio. Curso de direito administrativo. 28. ed. São Paulo: Malheiros, 2011.

BANDEIRA DE MELLO, Oswaldo Aranha. Princípios gerais do direito administrativo. 3 . ed. São Paulo: Malheiros, 2007. v. 1.

CARVALHO FILHO, José dos Santos. Manual de direito administrativo. 30. ed. São Paulo: Atlas, 2016.

CINTRA, Antônio Carlos de Araújo; GRINOVER, Ada Pellegrini; DINAMARCO, Candido Rangel. Teoria geral do processo. 27. ed. São Paulo: Malheiros, 2011.

DEZAN, Sandro Lucio. Nulidades no processo administrativo disciplinar. Curitiba: Juruá Editora, 2017.

DI PIETRO, Maria Sylvia Zanella. Discricionariedade administrativa na Constituição de 1988. São Paulo: Atlas, 1991.

DI PIETRO, Maria Sylvia Zanella. Tratado de direito administrativo: administração pública e servidores públicos. 2. ed. São Paulo: Thomson Reuters Brasil, 2019.

ENTERRÍA, Eduardo García; FERNÁNDEZ, Tomaz-Ramón. Curso de direito administrativo . São Paulo: Ed. RT, 2014.

GRECO, Rogério. Direito penal do equilíbrio: uma visão minimalista do direito penal. 5 . ed. Niterói: Impetus, 2010.

MEDAUAR, Odete. O direito administrativo em evolução. 3. ed. Brasília: Gazeta Jurídica, 2017. 
MIRANDA, Jorge. Teoria do estado e da constituição. Rio de Janeiro: Forense, 2001.

MOREIRA NETO, Diogo de Figueiredo. O direito administrativo no Século XXI. Belo Horizonte: Fórum, 2018.

NOBRE JÚNIOR, Edilson Pereira. As normas de direito público na Lei de Introdução ao Direito Brasileiro. São Paulo: Editora Contracorrente, 2019.

OSÓRIO, Fábio Medina. Direito administrativo sancionador. 7. ed. São Paulo: Thomson Reuters, 2020.

REALE, Miguel. Teoria do direito e do estado. 5. ed. São Paulo: Saraiva, 2000.

SEABRA FAGUNDES, Miguel. O controle dos atos administrativos pelo Poder Judiciário. 5. ed. Rio de Janeiro: Forense, 1979.

SILVA JÚNIOR, Walter Nunes da. Curso de direito processual penal: teoria (constitucional) do processo penal. Rio de Janeiro: Renovar, 2006.

TAVARES, André Ramos. Teoria da justiça constitucional. São Paulo: Saraiva, 2005.

Legislação

BRASIL, Constituição (1988). Constituição da República Federativa do Brasil. Brasília, DF: Senado Federal. Centro Gráfico, 1988.

BRASIL, Lei 9.784/1999 (LGL1999107). Regula o processo administrativo no âmbito da Administração Pública Federal. DF: Senado Federal, 1999.

BRASIL, Lei 8.112/1990 (LGL199046). Dispõe sobre o regime jurídico dos servidores públicos civil da União, das autarquias e das fundações públicas federais. DF: Senado Federal, 1991.

\section{Publicado}

2021-12-15

\section{Como Citar}

FRANÇA, V. da R. .; MORAIS, G. N. F. S. de. O processo administrativo disciplinar à luz da teoria do processo sancionador: The administrative disciplinary proceedings based on theory of sanctioning process. Revista de Direito Administrativo e Infraestrutura | RDAI, São Paulo: Thomson Reuters - Livraria RT, v. 5, n. 19, p. 73-99, 2021. DOI: 10.48143/rdai.19.vrf. Disponível em:

https://rdai.com.br/index.php/rdai/article/view/413. Acesso em: 7 fev. 2022.

\section{Edição}

V. 5…19_(2021) 



\section{Seção}

Direito Administrativo: Direito administrativo sancionador

\section{Licença}

\section{(c) $(1) \Theta(9$}

Este trabalho está licenciado sob uma licença Creative Commons Attribution-

NonCommercial-NoDerivatives 4.0 International License.

(CC BY-NC-ND).

Este é um resumo (e não um substituto) da licença

Regras para publicação

Direitrizes Editoriais

Direitos e Deveres

Errata e Retratação

Preservação e Plagiarismo

Revisão e Avaliaçãa 